\title{
Cymbopogon citratus essential oil: effect on polymicrobial caries-related biofilm with low cytotoxicity
}

\section{Maria Alcionéia Carvalho de OLIVEIRA ${ }^{\text {(a) }}$}

Aline Chiodi BORGES(b)

Fernanda Lourenção BRIGHENTI(c)

Marcos José SALVADOR(d)

Aline Vidal Lacerda GONTIJO(d)

Cristiane Yumi KOGA-ITO(b)

(a) Universidade Estadual Paulista -

Unesp, São José dos Campos Institute of

Science and Technology, Oral Biopathology

Graduate Program, São José dos Campos,

SP, Brazil.

(b) Universidade Estadual Paulista -

Unesp, São José dos Campos Institute

of Science and Technology, Department

of Environmental Engineering,

São José dos Campos, SP, Brazil.

(c) Universidade Estadual Paulista -

Unesp, Department of Orthodontics and

Pediatric Dentistry, Araraquara, SP, Brazil.

(d) Universidade Estadual de Campinas -

Unicamp, Institute of Biology, Department of

Plant Biology, Campinas, SP, Brazil.

Declaration of Interest: The authors certify that they have no commercial or associative interest that represents a conflict of interest in connection with the manuscript.

Corresponding author:

Cristiane Yumi Koga Ito

E-mail: cristiane@ict.unesp.br

Submitted: Apr 10, 2017

Accepted for publication: Aug 08, 2017

Last revision: Sep 22, 2017
Abstract: The objective of this study was to evaluate the effects of Cymbopogon citratus essential oil and its main compound (citral) against primary dental colonizers and caries-related species. Chemical characterization of the essential oil was performed by gas chromatography/mass spectroscopy (GC/MS), and the main compound was determined. Antimicrobial activity was tested against Actinomyces naeslundii, Lactobacillus acidophilus, S. gordonii, S. mitis, S. mutans, S. sanguinis and S. sobrinus. Minimum inhibitory and bactericide concentrations were determined by broth microdilution assay for streptococci and lactobacilli reference, and for clinical strains. The effect of the essential oil on bacterial adhesion and biofilm formation/disruption was investigated. Negative (without treatment) and positive controls (chlorhexidine) were used. The effect of citral on preformed biofilm was also tested using the same methodology. Monospecies and microcosm biofilms were tested. ANOVA or Kruskal-Wallis tests were used $(\alpha=0.05)$. Cytotoxicity of the essential oil to human keratinocytes was performed by MTT assay. GC/MS demonstrated one major component (citral). The essential oil showed an inhibitory effect on all tested bacterial species, including S. mutans and L. acidophilus. Essential oil of C. citratus (10X MIC) reduced the number of viable cells of lactobacilli and streptococci biofilms $(p<0.05)$. The essential oil inhibited adhesion of caries-related polymicrobial biofilm to dental enamel $(p<0.01)$. Citral significantly reduced the number of viable cells of streptococci biofilm $(p<0.001)$. The essential oil showed low cytotoxicity to human keratinocytes. Based on these findings, this study can contribute to the development of new formulations for products like mouthwash, against dental biofilms.

Keywords: Dental Caries; Biofilms; Phytotherapy; Microbiology; Tooth.

\section{Introduction}

Dental caries still affect children and adults worldwide. ${ }^{1}$ Three peaks of growing burden of untreated caries have recently been reported at ages 6,25 and 70,2 evidencing that this disease is still relevant in public health.

Microorganisms in dental biofilm are related to the initiation and progression of carious lesions. They adhere to dental surfaces and organize themselves functionally into communities, modifying the environment to favor their growth and survival. ${ }^{3}$ Fermentable carbohydrate-rich diet favors 
the proliferation of cariogenic species, producing considerable levels of lactic acid, ${ }^{4}$ which reduces the $\mathrm{pH}$ level and favors enamel demineralization, resulting in carious lesions. ${ }^{5}$

Mouthwashes and dentifrices are recommended for dental biofilm control as adjuncts to mechanical removal. ${ }^{6,7}$ Chlorhexidine digluconate is considered the gold standard antimicrobial substance. ${ }^{8}$ Nonetheless, the occurrence of adverse effects, such as dental staining and hypersensitivity reactions, has encouraged the search for new molecules. ${ }^{8}$

The promising potential of natural substances against cariogenic microorganisms, and their application in the development of preventive and therapeutic products, has been explored in recent years. ${ }^{9,10}$ There are already some commercially available formulations of mouthwashes and dentifrices containing natural substances. ${ }^{11,12}$ Previous studies have reported the effects of natural substances on microbial growth, polysaccharides synthesis and dental biofilm formation. ${ }^{13}$ Essential oils are complex mixtures of volatile hydrophobic substances obtained from secondary plant metabolites. In general, their antimicrobial effects are related to alterations in the permeability and integrity of bacterial cell membranes. ${ }^{14}$

A recent study ${ }^{15}$ showed the antimicrobial activity of Cymbopogon citratus (Poaceae) extract on standard strains and clinical streptococci isolates. Additionally, previous studies ${ }^{16,17,18}$ tested the activity of $C$. citratus essential oil on Streptococcus mutans monospecies biofilm. These studies pointed to the promising potential of this natural substance for application in anti-caries products. Nonetheless, considering the complexity of cariogenic biofilm formation, further in-depth studies are still needed to support clinical application. The effects of this substance on the biofilm formation process, polymicrobial caries-related biofilm and other cariogenic species are still unknown.

To the best of our knowledge, this is the first study to evaluate the effects of C. citratus essential oil on polymicrobial biofilms involved in the initiation/progression of dental caries. We also aimed to evaluate its effects on dental primary colonizers, adhesion to dental enamel and microcosm biofilm formation. Chemical characterization and cytotoxicity evaluation of the essential oil were also performed.
Lastly, an investigation was made into whether citral, the main isolated compound of the essential oil, is responsible for its bioactivity.

\section{Material and methods}

\section{Essential oil and isolated compound}

The essential oil of $C$. citratus leaves was obtained commercially from Laszlo Aromaterapia Ltda. (Belo Horizonte, Brazil). Citral was purchased from Sigma-Aldrich Co. (St. Louis, USA).

\section{Chemical analysis of the essential oil}

Chemical characterization was performed using gas chromatography/mass spectroscopy (GC/MS) (Shimadzu, Japan). Gas chromatography with electron impact mass spectrometry (GC/EIMS) $(70 \mathrm{eV})$ analysis was carried out using a Shimadzu GC/MS spectrometer (GC-2010). A Durabond-DB5 capillary column ( $30 \mathrm{~m} \times 0.25 \mathrm{~mm}, 0.25 \mu \mathrm{m}$ film thickness) (J\&W Scientific) was operated at $60^{\circ} \mathrm{C}$ for $3 \mathrm{~min}$ and then programmed for $60-220^{\circ} \mathrm{C}$ at $5^{\circ} \mathrm{C} / \mathrm{min}$, after which it was kept under isothermal conditions at $220^{\circ} \mathrm{C}$ for $5 \mathrm{~min}$. The carrier gas was helium (purity of $99.99 \%$ ) $(1 \mathrm{ml} / \mathrm{min})$, and the injector temperature was $250^{\circ} \mathrm{C}$. The analyses were performed in a split injector mode (1:30). The essential oil components were identified by comparing their retention indexes (relative to n-alkanes) and mass spectra with those found in the literature. ${ }^{19,20}$ They were then stored in a spectrometer database. The analyses were performed in triplicate.

\section{Microorganisms and growth conditions}

All of the experiments involving microorganisms used brain heart infusion (BHI) broth (Himedia, Mumbai, India) with propylene glycol (9:1, v/v) as the negative control, and $1.2 \mathrm{mg} \mathrm{ml}^{-1}$ chlorhexidine digluconate (Periogard, Colgate-Palmolive ${ }^{\circledR}$, São Paulo, Brazil) as the positive control. These experiments were done in duplicate.

The following reference strains were included in this study: Actinomyces naeslundii ATCC 19039, Lactobacillus acidophilus ATCC 4356, Lactobacillus acidophilus ATCC 10558, Streptococcus mitis ATCC 9811, S. mutans ATCC 35688, Streptococcus sanguinis ATCC 10556 and Streptococcus sobrinus ATCC 33478. The samples were 
kept in BHI broth (Himedia, Mumbai, India) and 20\% (v/v) glycerol (Synth, Diadema, Brazil) at $-80^{\circ} \mathrm{C}$.

The samples were plated on BHI agar for $24 \mathrm{~h}$ (all streptococci and L. acidophilus) or $72 \mathrm{~h}$ (A. naeslundii) prior to the experiment. The following oxygen tensions were used throughout the experiment: A. naeslundii: oxygen-free atmosphere generated by AnaeroGen (Oxoid); lactobacilli: aerobiosis; and streptococci: $5 \% \mathrm{CO}_{2}$. All incubations were performed at $37^{\circ} \mathrm{C}$.

After this period, standardized suspensions containing $10^{7}$ cells $\mathrm{ml}^{-1}$ in saline solution $(\mathrm{NaCl}$ 0.9\%) (Synth, Diadema, Brazil) were prepared using a spectrophotometer (B-582, Micronal, São Paulo, Brazil). Previously standardized wavelength and optical density parameters were used: $S$. mutans and S. sobrinus $\mathrm{A}_{398}=0.620 ; S$. sanguinis and S. mitis $\mathrm{A}_{398}=0.720 ;$ S. gordonii $\mathrm{A}_{398}=0.520 ;$ A. naeslundii $\mathrm{A}_{550}=0.125$; and L. acidophilus $\mathrm{A}_{307}=0.269$.

Additionally, clinical isolates of mutans streptococci $(n=12)$ and lactobacilli $(n=20)$ were obtained from carious dentine. The samples were collected from carious lesions of molars of 20 children, aged 5 to 11 years. The Local Ethics Committee previously approved these procedures (protocol \#096/2011-PH/CEP). The carious dentine was collected with the aid of a curette, and transferred to tubes containing $1 \mathrm{ml}$ of phosphate-buffered saline (PBS, pH 7.0) solution. The samples were homogenized under sonication, and a volume of $0.1 \mathrm{ml}$ was plated in Mitis Salivarius sucrose bacitracin agar (Himedia, Mumbai, India) and Rogosa agar (Himedia, Mumbai, India), supplemented with glacial acetic acid (Synth, Diadema, Brazil) to isolate mutans streptococci and lactobacilli, respectively. The plates were incubated for $48 \mathrm{~h}$ at $37^{\circ} \mathrm{C}$ and $5 \% \mathrm{CO}_{2}$. Pure isolates were obtained and stored in $\mathrm{BHI} 15 \%$ glycerol at $-80^{\circ} \mathrm{C}$ until use.

Finally, stimulated human saliva was collected from 2 volunteers to establish an in vitro polymicrobial biofilm, according to a previously described methodology. ${ }^{21}$ The protocol was previously approved by the Local Ethics Committee (protocol \#096/2011-PH/CEP). Stimulated saliva $(20 \mathrm{ml})$ was collected and filtered in sterile gauze to remove solid residues. The saliva was maintained on ice during the procedure. Next, the saliva was diluted in sterile glycerol 7:3 (v/v) and stored at $-20^{\circ} \mathrm{C}$ until use.

\section{Agar well diffusion test}

The susceptibility of the reference strains (A. naeslundii ATCC 19039, L. acidophilus ATCC 4356, S. gordonii ATCC 10558, S. mitis ATCC 9811, S. mutans ATCC 35688, S. sanguinis ATCC 10556 and S. sobrinus ATCC 33478) to the essential oil in its pure form was evaluated by the double-layer agar well diffusion test, using previously described methodology. ${ }^{22}$ Growth inhibition halos were measured after incubation for $24 \mathrm{~h}$ using a colony counter with $1.5 \mathrm{X}$ magnification (CP 600 Plus, Phoenix, Brazil). The data were analyzed using descriptive statistics.

\section{Minimum Inhibitory (MIC) and Bactericide Concentration (MBC) determination}

The minimum inhibitory concentrations (MIC) and minimum bactericide concentrations (MBC) were determined for reference strains and clinical isolates of Streptococcus spp. and Lactobacillus spp. MIC and $\mathrm{MBC}$ were determined using the microdilution reference method recommended by the Clinical and Laboratory Standards Institute (CLSI) M07-A9, ${ }^{23}$ with modifications. Concentrations ranging from 0.08 to $50 \mathrm{mg} \mathrm{ml}^{-1}$ of essential oil and 0.078 to $43 \mathrm{mg} \mathrm{ml}^{-1}$ of citral were obtained in culture medium (BHI broth). After the inoculation of standardized suspensions $(10 \mu \mathrm{l})$, the microtiter plates were incubated for $24 \mathrm{~h}$. MIC was determined by visual reading, compared with growth control. The MIC values were determined as the minimum concentration able to inhibit $50 \%$ of bacterial growth. Subcultures in the BHI agar of all wells were made for the purpose of determining MBC, and thus evaluate bacterial growth. Chlorhexidine digluconate (Periogard, Colgate-Palmolive ${ }^{\circledR}$, São Paulo, Brazil) was used as the positive control.

The data were analyzed using descriptive statistics. Cumulative inhibition was calculated to express the results obtained for the clinical isolates.

\section{Effects of the essential oil on bacterial adhesion to human dental enamel}

The teeth included in the study were extracted from patients under treatment at São José dos Campos Dental School for periodontal or prosthetic reasons. This protocol was approved by the Local Ethics Committee (protocol \#096/11-PH/CEP). The teeth were disinfected 
and cleaned, so as to remove biofilm and dental calculus. Standardized specimens of $2 \times 2 \mathrm{~mm}$ were obtained, and the dentine was isolated with nail varnish (Colorama, L'Oreal, São Paulo, Brazil). The specimens were sterilized using gamma-cobalt 60 radiation (25 kGy/6h; IPEN-CNEN/SP, São Paulo, Brazil).

The specimens were randomly divided into 3 groups $(n=15): C$. citratus essential oil, positive control (mouthwash containing $1.2 \mathrm{mg} \mathrm{ml}^{-1}$ chlorhexidine digluconate) and negative control. Enamel samples were transferred to 96 -well plates containing $75 \mu \mathrm{l}$ of BHI, supplemented either with $75 \mu$ l of a sub-inhibitory concentration ( $50 \% \mathrm{MIC})$ of the essential oil, or with the controls plus $3 \mu$ l of inoculum of the polymicrobial species.

After incubation for $24 \mathrm{~h}$ under anaerobiosis and agitation $(80 \mathrm{rpm})$, the specimens were transferred to tubes containing $2 \mathrm{ml}$ of saline, and the cells that adhered to the enamel surface were dispersed by vortexing ( 1 minute) and sonication ( 3 cycles of $15 \mathrm{~s}$ with an interval of $10 \mathrm{~s}$; amplitude 50; $15 \mathrm{~W}$ ) (Misonix Inc., NY, USA). The suspension was diluted, and $0.1 \mathrm{ml}$ was inoculated in BHI agar. The plates were incubated for $24 \mathrm{~h}$ under anaerobiosis. Afterwards, the colony forming units (CFUs)/specimen were determined.

\section{Effects of the essential oil on preformed biofilm (short treatment exposure time)}

Biofilms of reference strains and clinical isolates were formed on glass coverslips (Kasvi, Curitiba, Brazil) suspended in a 12-well cell culture plate. The microorganisms used were S. mutans ATCC 35688, L. acidophilus ATCC 4356, and five selected clinical isolates of mutans streptococci and lactobacilli obtained from carious dentine, as described above.

Volumes of $1.5 \mathrm{ml} \mathrm{BHI} \mathrm{plus} \mathrm{20 \%} \mathrm{sucrose} \mathrm{(Synth,}$ Diadema, Brazil) and $30 \mu \mathrm{L}$ of the inoculum were added to each well. The plates were incubated for up to $48 \mathrm{~h}$ at $37^{\circ} \mathrm{C}\left(5 \% \mathrm{CO}_{2}\right.$ for mutans streptococci), in an orbital shaker table (Inbras-Eriez Equipamentos, Diadema, Brazil) at $80 \mathrm{rpm}$. The culture medium was changed after 8 hours (for maintenance of adherent cells only), and then $24 \mathrm{~h}$ after start of incubation.

After $48 \mathrm{~h}$ of incubation, the coverslips containing the biofilms were washed in sterile saline solution and subsequently exposed to the essential oil in concentrations of 2, 4 and 10 times the MIC for 60 seconds. The negative control was not submitted to any treatment, and the positive control was treated with mouthwash containing chlorhexidine digluconate at $1.2 \mathrm{mg} \mathrm{ml}^{-1}$.

After treatment, the coverslips were washed in sterile saline solution and sterile distilled water, and subsequently transferred to tubes containing $8 \mathrm{ml}$ of saline. The coverslips were vortexed for 1 minute and sonicated for $5 \mathrm{~min}$ to dissipate the adhered cells in the biofilm. The resulting suspension was serially diluted, and plated onto BHI agar. After incubation for $24 \mathrm{~h}$ at $37^{\circ} \mathrm{C}\left(5 \% \mathrm{CO}_{2}\right.$ for $S$. mutans), the $\mathrm{CFU} /$ specimen values were obtained. All the tests were performed in duplicate.

\section{Effects of the essential oil on preformed polymicrobial biofilm (medium treatment exposure time)}

Microcosm polymicrobial biofilms from saliva were formed on glass discs (ø $13 \mathrm{~mm}$, Glasscyto, São Paulo, Brazil) and a custom-designed lid was used to attach the glass discs to the standard 24-well plates, as described by Exterkate et al. ${ }^{24}$ After $48 \mathrm{~h}$ of incubation, the biofilms were washed in saline solution and immersed in a solution of essential oil/propylene glycol at 2, 4 and 10 times the MIC of C. citratus essential oil for $60 \mathrm{~min}$. The experiments were performed in duplicate. Mouthwash containing chlorhexidine digluconate at $1.2 \mathrm{mg} \mathrm{ml}^{-1}$ was used as the positive control. The negative control specimens were immersed in sterile distilled water.

After 60 minutes of treatment, the glass discs were washed in saline solution and the biofilms were re-suspended in saline by vortexing (1 minute) and sonication (3 cycles of $15 \mathrm{~s}$ each, with a 10s interval between each cycle; amplitude 50; 15 W) (Misonix Inc., Farmingdale, USA). The suspension was diluted, and $0.1 \mathrm{ml}$ was inoculated into BHI agar. The plates were incubated for $24 \mathrm{~h}$ under anaerobiosis After this period, the number of colonies was obtained and the CFUs/specimen were calculated. All the tests were performed in duplicate.

\section{Effect of citral (major compound) on biofilm formed on dental enamel specimens}

The biofilm on dental enamel specimens was formed with S. mutans ATCC 35688, which is supposedly the most difficult to treat, since it presents 
a higher MIC value. The teeth used in this procedure were obtained and prepared as described above.

Tooth fragments $(n=12)$ were placed in a 24-well cell culture plate containing $1.5 \mathrm{~mL}$ of BHI broth and $30 \mu \mathrm{L}$ of the inoculum. The growth conditions were the same as the biofilm on the glass coverslips, as described above. The negative control group $(\mathrm{n}=12)$ was not exposed to any treatment, and the positive control group $(n=12)$ was exposed to mouthwash containing $1.2 \mathrm{mg} \mathrm{ml}^{-1}$ chlorhexidine digluconate. After treatment ( 60 seconds), the dental enamel specimens were transferred to tubes containing $1 \mathrm{ml}$ of saline solution, and the adhered cells were dispersed by vortexing (1 minute) and sonication. The resulting suspension was serially diluted, inoculated into $\mathrm{BHI}$ agar and incubated at $37^{\circ} \mathrm{C}$ in $5 \% \mathrm{CO}_{2}$ for 24 $\mathrm{h}$ to obtain the $\mathrm{CFU} /$ specimen values.

\section{Cytotoxicity assay of the essential oil}

A human keratinocyte (HaCaT) cell line was grown in Roswell Park Memorial Institute (RPMI) 1640 Medium (Gibco BRL, Life Technologies), supplemented with $5 \%$ of inactivated fetal bovine serum (FBS) (Cripion Biotecnologia LTDA, Andradina, Brazil) and penicillin: streptomycin (Sigma, Detroit, USA) $(1000 \mu \mathrm{g} / \mathrm{ml}$ : $1000 \mathrm{UI} / \mathrm{ml}, 1 \mathrm{ml} / \mathrm{l})$. The cells $\left(3.6 \times 10^{4}\right.$ cells $/ \mathrm{ml}, 100 \mu \mathrm{l}$ cells/well) were exposed to varying concentrations of essential oil (0.25-250 $\mu \mathrm{g} / \mathrm{ml}, 100 \mu \mathrm{l} /$ well) in 96-well plates (Kasvi, Curitiba, Brazil), with dimethyl sulfoxide (DMSO)/RPMI1640 (1:99, v/v), and were maintained at $37^{\circ} \mathrm{C}$ in $5 \% \mathrm{CO}_{2}$ for $48 \mathrm{~h}$. Before and after $48 \mathrm{~h}$, the bioactivity was evaluated using the MTT colorimetric method at $570 \mathrm{~nm} .{ }^{25}$ Untreated cells and DMSO/RPMI 1640-FBS5\% (1:99, v/v) were used as the negative control. Doxorubicin at $50 \mu \mathrm{g} / \mathrm{ml}$ was included as the positive control. This experiment was performed in triplicate.

The results were expressed as a percentage of viable cells (\%), using the number of cells grown in wells without compounds as the negative control.

\section{Statistical analyses}

Data of the number of $S$. mutans cells in biofilms after treatment with citral and the control groups were compared by one-way ANOVA and Tukey's Multiple Comparison post hoc test, or Kruskal-Wallis and Dunn's Multiple Comparison Test. The level of significance was set at $5 \%$.

\section{Results}

\section{Chemical analysis of the essential oil}

The CG/MS analysis of the essential oil showed the presence of cis-citral or neral (34.1\%) and trans-citral or geranial (46.6\%) monoterpenes. Citral, in its cis and trans forms, thus was the major component responsible for more than $80 \%$ of the oil composition (Table 1).

The compounds are listed in order of their elution from a DB-5 column; the coefficients of variation obtained in these analyses were below $5 \%$. a) Identification based on mass spectra, RI and computer matching of the mass spectra with the NIST 1998 library (quality level greater than 90\%);

Table 1. Chemical composition (\%) of Cymbopogon citratus leaf essential oil.

\begin{tabular}{|c|c|c|c|c|}
\hline Number & Compound $^{a}$ & $\mathrm{RI}^{\mathrm{b}}$ & $\mathrm{Rl}^{\mathrm{c}}$ & $\begin{array}{c}\text { Composition } \\
(\%)\end{array}$ \\
\hline 1 & 6-methyl-5-hepten-2-one & 987 & 985 & 1.1 \\
\hline 2 & b-myrcene & 992 & 991 & 6.8 \\
\hline 3 & cis-beta-ocimene & 1038 & 1040 & 0.2 \\
\hline 4 & trans-beta-ocimene & 1048 & 1050 & 0.2 \\
\hline 5 & Linalool & 1101 & 1098 & 1.0 \\
\hline 6 & trans-2,8-mentadienol & 1106 & 1111 & 0.2 \\
\hline 7 & Verbenol & 1141 & 1140 & 0.2 \\
\hline 8 & trans- chrysanthemal & 1151 & 1150 & 0.4 \\
\hline 9 & Citronellal & 1154 & 1153 & 0.3 \\
\hline 10 & b-terpineol & 1166 & 1159 & 0.9 \\
\hline 11 & a-terpineol & 1184 & 1189 & 1.5 \\
\hline 12 & cis-citral (neral) & 1248 & 1240 & 34.1 \\
\hline 13 & Geraniol & 1259 & 1255 & 1.1 \\
\hline 14 & trans-citral (geranial) & 1279 & 1270 & 46.6 \\
\hline 15 & 2-undecanone & 1296 & 1291 & 0.2 \\
\hline 16 & b-caryophyllene & 1424 & 1418 & 0.2 \\
\hline 17 & a-trans-bergamoteno & 1439 & 1436 & 0.2 \\
\hline 18 & 2-tridecanona & 1497 & 1496 & 0.3 \\
\hline 19 & caryophyllene oxide & 1589 & 1583 & 0.1 \\
\hline 20 & seline-6-en-4-ol & 1625 & 1615 & 0.1 \\
\hline \multirow[t]{5}{*}{21} & cembrene $\mathrm{A}$ & 1960 & 1959 & 0.4 \\
\hline & \multicolumn{3}{|l|}{ Total identified } & 96.1 \\
\hline & \multicolumn{3}{|l|}{ Monoterpenes } & 71.0 \\
\hline & \multicolumn{3}{|l|}{ Sesquiterpenes hydrocarbons } & 3.7 \\
\hline & \multicolumn{3}{|l|}{ Oxygenated sesquiterpenes } & 19.2 \\
\hline
\end{tabular}


b) published retention index; c) experimental retention index on a DB- 5 column. The major components are identified in bold.

\section{Agar well diffusion test}

C. citratus essential oil showed inhibitory effects on the tested reference strains in the agar well diffusion test, with halo diameters ranging from 8 to $16 \mathrm{~mm}$ (Table 2). The negative control used as the diluent (propylene glycol) for the essential oil showed no inhibitory activity against the evaluated microorganisms.

\section{Determining Minimum Inhibitory Concentration (MIC) and Minimum Bactericide Concentration (MBC)}

The MIC and MBC values obtained for the reference strains are shown in Table 3. The inhibitory and bactericidal activities were observed against all tested species. The MIC values ranged from 1.32 to $2.61 \mathrm{mg} \mathrm{ml}^{-1}$ for the essential oil, and from 0.02 to $0.18 \mathrm{mg} \mathrm{ml}^{-1}$ for the positive control (chlorhexidine digluconate). The MBC values ranged from 2.61 to $10.54 \mathrm{mg} \mathrm{ml}^{-1}$ for the essential oil, and from 0.04 to $0.18 \mathrm{mg} \mathrm{ml}^{-1}$ for the positive control. The MIC and $M B C$ values for the isolated compound (citral) ranged from 1.33 and $11.1 \mathrm{mg} \mathrm{ml}^{-1}$, respectively (Table 3).

C. citratus essential oil showed bactericidal and bacteriostatic effects against all clinical isolates of Lactobacillus spp. and mutans streptococci (Figure 1a). Among the lactobacilli clinical isolates, $70 \%$ showed MIC values lower than or equal to the reference strain (1.32 $\mathrm{mg} \mathrm{ml}^{-1}$ ), and $60 \%$ showed $\mathrm{MBC}$ values lower than or equal to the reference strain $\left(2.61 \mathrm{mg} \mathrm{ml}^{-1}\right)$. As for the positive control (chlorhexidine digluconate), $90 \%$ the oral isolates showed MIC values lower than or equal to those of the reference strain $\left(0.02 \mathrm{mg} \mathrm{ml}^{-1}\right)$, and $100 \%$ of the oral isolates showed MBC values lower than or equal to the reference strains $\left(0.09 \mathrm{mg} \mathrm{ml}^{-1}\right)$ (Figure $\left.1 b\right)$.

In regard to the oral isolates of mutans streptococci, $33 \%$ showed MIC values lower than or equal to the reference strain $\left(2.61 \mathrm{mg} \mathrm{ml}^{-1}\right)$, whereas $92 \%$ showed $\mathrm{MBC}$ values lower than or equal to the reference strain (10.54 mg ml-1) (Figure 1c). As for the chlorhexidine digluconate, $42 \%$ of the oral isolates showed MIC and MBC values lower than or equal to those of the reference strain (0.04 and $0.18 \mathrm{mg} \mathrm{ml}^{-1}$, respectively) (Figure 1d).

\section{Effects of the essential oil on bacterial adhesion to human dental enamel}

Essential oil and mouthwash containing chlorhexidine digluconate at $1.2 \mathrm{mg} \mathrm{ml}^{-1}$ reduced the number of adhered cells ( $\mathrm{n}=15$ for each group) $100 \%$ and $69 \%$, respectively. The mean \pm SD values (CFU/specimen) of adhered cells for the control, essential oil at $1 / 2$ MIC and mouthwash containing chlorhexidine digluconate at $1.2 \mathrm{mg} \mathrm{ml}^{-1}$ were, respectively, $(8.7 \pm 10.7) \times 10^{6}, 0,(2.7 \pm 8.0) \times 10^{5}$. The difference between the essential oil group and the

Table 2. Inhibition halos (average; $\mathrm{mm}$ ) obtained from C. citratus essential oil $(9: 1(\mathrm{v} / \mathrm{v})$ in propylene glycol) and the positive control (mouthwash containing chlorhexidine digluconate at $1.2 \mathrm{mg} \mathrm{ml}^{-1}$ ) against the reference strains.

\begin{tabular}{lcc}
\hline Microorganisms & $\begin{array}{c}\text { Essential } \\
\text { oil }\end{array}$ & $\begin{array}{c}\text { Positive } \\
\text { control }\end{array}$ \\
\hline Streptococcus mutans ATCC 35688 & 11 & 17 \\
Streptococcus gordonii ATCC 10558 & 10 & 20 \\
Streptococcus sanguinis ATCC 10556 & 10 & 19 \\
Streptococcus. sobrinus ATCC 33478 & 11 & 24 \\
Streptococcus mitis ATCC 981 1 & 19 & 22 \\
Lactobacillus acidophilus ATCC 4356 & 8 & 13 \\
Actinomyces naeslundii ATCC 19039 & 16 & 25 \\
\hline
\end{tabular}

Table 3. Minimum inhibitory concentration (MIC) and minimum bactericide concentration (MBC) $\left(\mathrm{mg} \mathrm{ml}^{-1}\right)$ of $C$. citratus essential oil (1:9 (v/v in propylene glycol), the isolated compound (citral) and the positive control (mouthwash containing chlorhexidine digluconate at $1.2 \mathrm{mg} \mathrm{m}^{-1}$ ) against the reference strains.

\begin{tabular}{llllllll}
\hline \multirow{2}{*}{ Microorganisms } & \multicolumn{2}{c}{ Essential oil } & \multicolumn{2}{c}{ Citral } & \multicolumn{3}{c}{ Positive control } \\
\cline { 2 - 7 } & MIC & MBC & MIC & MBC & MIC & MBC \\
\hline $\begin{array}{l}\text { Streptococcus mutans } \\
\text { ATCC 35688 }\end{array}$ & 2.61 & 10.54 & 2.75 & 11.1 & 0.04 & 0.18 \\
$\begin{array}{l}\text { Streptococcus gordonii } \\
\text { ATCC 10558 }\end{array}$ & 1.32 & 5.23 & NA & NA & 0.09 & 0.18 \\
$\begin{array}{l}\text { Streptococcus } \\
\text { sanguinis ATCC 10556 }\end{array}$ & 2.61 & 10.54 & NA & NA & 0.04 & 0.09 \\
$\begin{array}{l}\text { Streptococcus. sobrinus } \\
\text { ATCC 33478 }\end{array}$ & 2.61 & 10.54 & NA & NA & 0.02 & 0.04 \\
$\begin{array}{l}\text { Streptococcus mitis } \\
\text { ATCC 9811 }\end{array}$ & 2.61 & 5.23 & NA & NA & 0.18 & 0.18 \\
$\begin{array}{l}\text { Lactobacillus acidophilus } \\
\text { ATCC 4356 }\end{array}$ & 1.32 & 2.61 & 1.33 & 2.75 & 0.02 & 0.09 \\
$\begin{array}{l}\text { Actinomyces naeslundii } \\
\text { ATCC 19039 }\end{array}$ & 1.32 & 5.23 & NA & NA & 0.02 & 0.04 \\
\hline NA: not avalable & & & & & & \\
\hline
\end{tabular}

NA: not available 
A) Lactobacillus spp.

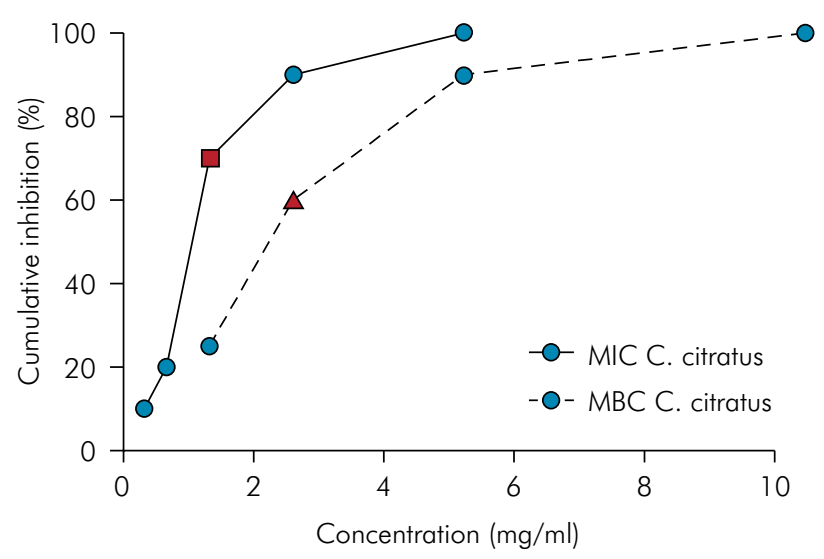

C) Streptococcus mutans

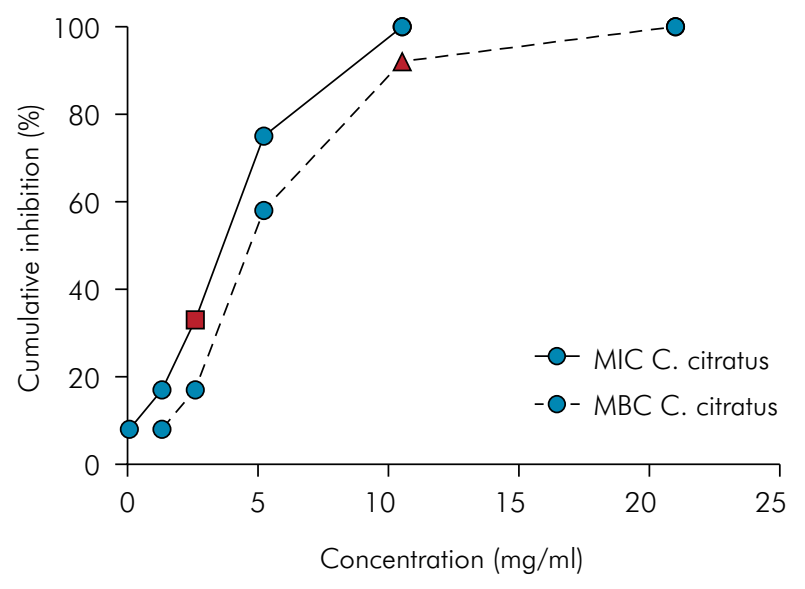

B) Lactobacillus spp.

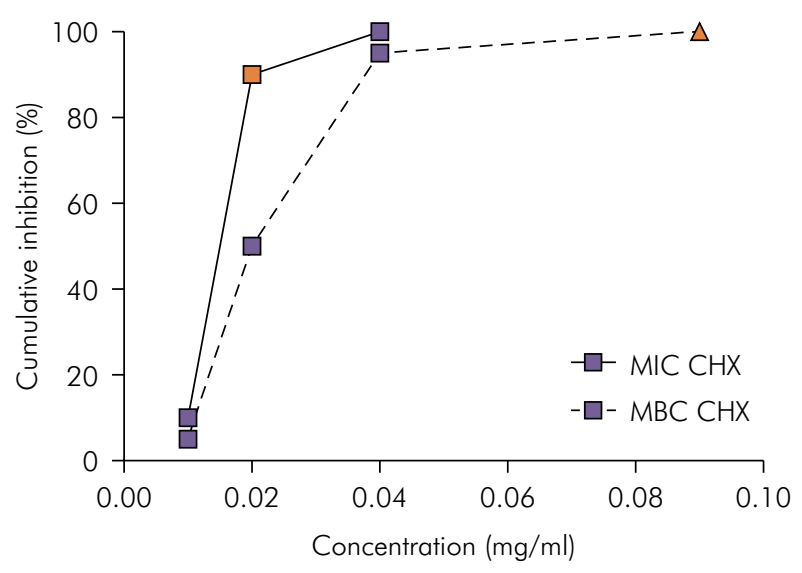

D) Streptococcus mutans

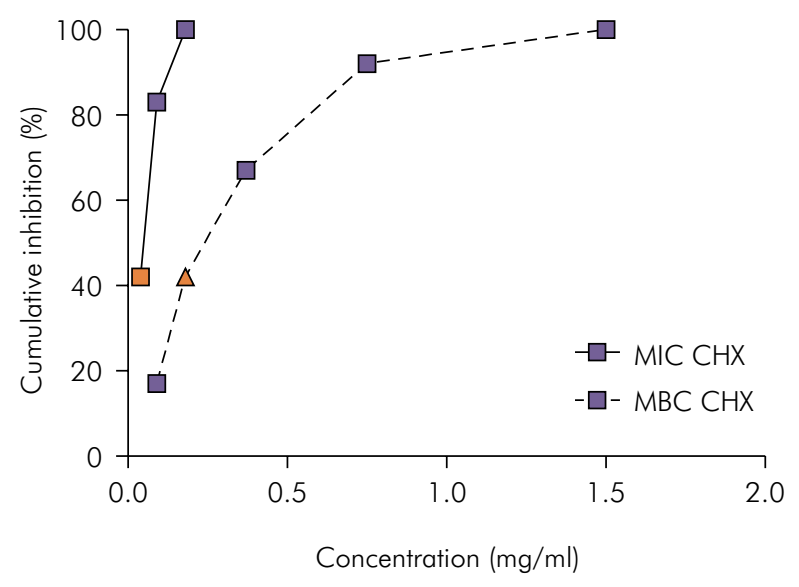

Figure 1. Cumulative inhibition for the minimum inhibitory concentration (MIC; solid lines) and minimum bactericidal concentration (MBC; dotted lines) of $C$. citratus essential oil (circular markers) and the positive control (chlorhexidine digluconate, $\mathrm{CHX}$; squared markers). A) MIC and MBC of the essential oil for clinical isolates of Lactobacillus spp.; B) MIC and MBC of chlorhexidine digluconate (positive control) for clinical isolates of Lactobacillus spp.; C) MIC and MBC of the essential oil for clinical isolates of mutans streptococci; D) MIC and MBC of chlorhexidine digluconate (positive control) for clinical isolates of mutans streptococci. MIC and $M B C$ values for reference strains are highlighted with gray squares and triangles respectively.

mouthwash containing chlorhexidine digluconate at $1.2 \mathrm{mg} \mathrm{ml}^{-1}$ group was statistically significant, with a $p$ value lower than 0.05 (Kruskal-Wallis/ Dunn's test). The difference between the essential oil and the positive control groups was statistically significant as well, with a $p$ value lower than 0.0001 (Kruskal-Wallis/ Dunn's test).

\section{Effects of the essential oil on preformed biofilm (short treatment exposure time)}

After a short treatment exposure time (60 seconds), there was a reduction in the number of viable cells of the lactobacilli biofilm after all treatments. The mean \pm SD (CFU/specimen) values for the control, essential oil at 2X, 4X and 10X MIC and mouthwash containing chlorhexidine digluconate at $1.2 \mathrm{mg} \mathrm{ml}^{-1}$ were, respectively, $(4.9 \pm 6.7) \times 10^{8},(2.3 \pm 3.0) \times 10^{7},(1.9 \pm 3.2) \times 10^{7}$, $(2.0 \pm 2.5) \times 10^{6}$ and $(1.0 \pm 2.2) \times 10^{7}$. However, this reduction was statistically significant ( $p$ value lower than 0.01 , Kruskal-Wallis/ Dunn's test) only for essential oil of C. citratus at 10 times the MIC (Figure 2a).

There was also a reduction in the number of viable cells of the streptococci biofilm after all treatments. The mean \pm SD (CFU/specimen) values for the control, 
essential oil at 2X, 4X and 10X MIC and mouthwash containing chlorhexidine digluconate at $1.2 \mathrm{mg}$ $\mathrm{ml}^{-1}$ were, respectively, $(7.4 \pm 8.3) \times 10^{8},(2.4 \pm 5.3) \times 10^{8}$, $(9.5 \pm 20.8) \times 10^{7},(4.1 \pm 9.4) \times 10^{7}$ and $(1.7 \pm 2.7) \times 10^{8}$. However, this reduction was statistically significant ( $p$ value lower than 0.05 , Kruskal-Wallis/ Dunn's test) only for essential oil of $C$. citratus at 10 times the MIC (Figure 2b). Essential oil at 10 times the MIC induced a higher reduction in the number of viable cells than mouthwash containing chlorhexidine digluconate for Lactobacillus ssp. and S. mutans biofilms, although there was no statistical difference between them.

\section{Effects of the essential oil on preformed polymicrobial biofilm (medium treatment exposure time)}

In the polymicrobial biofilms formed on the glass surface, the number of viable cells was reduced after treatment for 60 minutes with essential oil at 2, 4 and 10 times the MIC for reference strains. The negative control recorded no activity on the biofilms. The mean $\pm \mathrm{SD}$ (CFU/specimen) values for the control, essential oil at 2X, $4 \mathrm{X}$ and 10X MIC and mouthwash containing chlorhexidine digluconate at $1.2 \mathrm{mg} \mathrm{ml}^{-1}$ were, respectively, $(1.4 \pm 0.3) \times 10^{7}, 0,0$,
0 and $(1.2 \pm 0.2) \times 10^{5}$. The viable cell reduction in the treatment groups (essential oil and chlorhexidine) was statistically significant ( $p$ value lower than 0.01 , ANOVA/ Tukey's test).

\section{Effect of citral (major compound) on biofilm formed on dental enamel specimens}

Treatment of $S$. mutans biofilm on dental enamel with $27.5 \mathrm{mg} \mathrm{ml}^{-1}$ of citral and mouthwash containing chlorhexidine digluconate at $1.2 \mathrm{mg} \mathrm{ml}^{-1}$ significantly reduced the number of viable cells $(\mathrm{p}<0.001)$ (Figure 3). There was no significant difference between these treatments $(p>0.05)$.

\section{Cytotoxicity assay of essential oil}

The cytotoxic effect of $C$. citratus essential oil against a human keratinocyte (HaCaT) cell line was evaluated in the range of 0.25 to $25 \mathrm{mg} \mathrm{ml}^{-1}$. After exposure to $0.25 \mathrm{mg} \mathrm{ml}^{-1}$, the cell viability rate was $98 \%$; this value reached $85 \%$ in the presence of $25 \mathrm{mg}$ $\mathrm{ml}^{-1}$ (10 times the MIC) of oil. The negative control, DMSO/RPMI 1640 (1:99, v/v), did not affect the cell viability of $100 \%\left(3.6 \times 10^{4}\right.$ cells $\left./ \mathrm{ml}\right)$. Doxorubicin at $50 \mu \mathrm{g} / \mathrm{ml}$, used as the positive control, showed a cell viability of $0 \%$.
A) Lactobacillus spp.

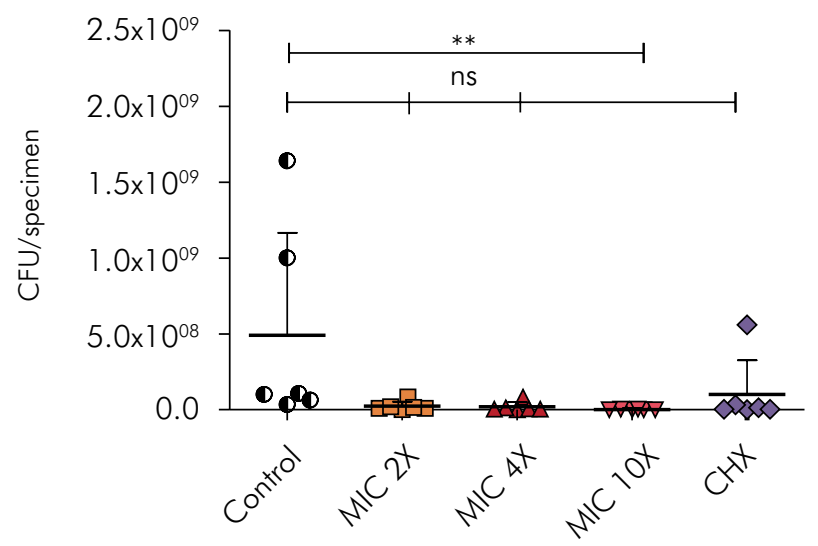

B) Streptococcus mutans

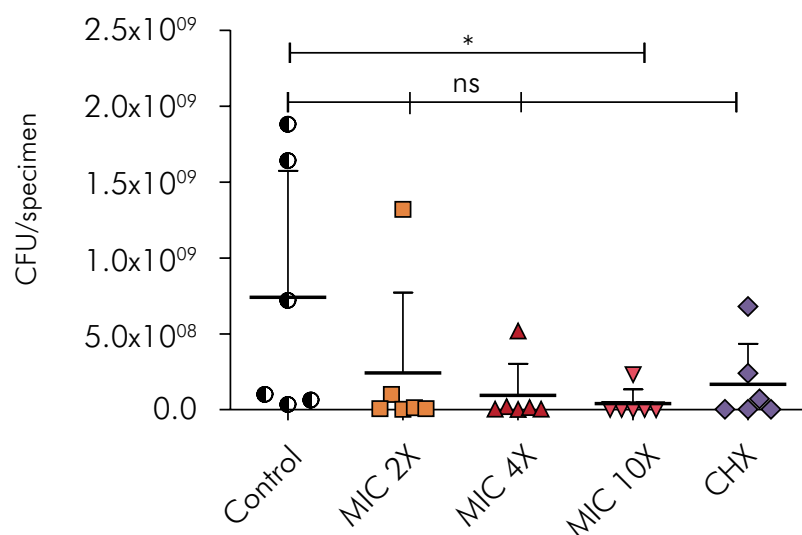

Figure 2. CFU/specimen in biofilm formed with reference strains and clinical isolates treated for 60 seconds after 48 hours of growth. A) Lactobacilli biofilm: MIC 2X, 4X and 10X of essential oil: 2.64, 5.28 and $13.2 \mathrm{mg} \mathrm{ml}^{-1}$ respectively; B) Streptococci biofilm: MIC 2X,4X and 10X of essential oil: 5.22, 10.44 and $26.10 \mathrm{mg} \mathrm{ml}^{-1}$ respectively. CHX: mouthwash containing $1.2 \mathrm{mg} \mathrm{ml}^{-1}$ of chlorhexidine digluconate (positive control). The mean \pm SD ( $\mathrm{n}=6$ for each group) was shown in the scatter plot. Kruskal-Wallis test and Dunn's Multiple Comparison test were used to compare data against the control data. ${ }^{*} p<0.05$; ${ }^{* *} \mathrm{p}<0.01$; ns: not significant. 


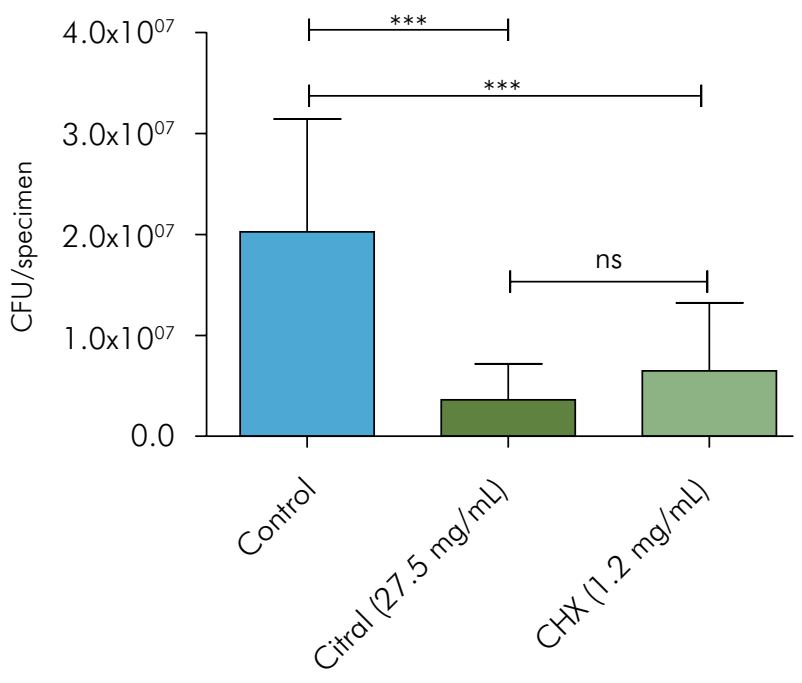

Figure 3. CFU / specimen of S. mutans ATCC 35688 biofilm in dental enamel without treatment (Negative Control, $n=11)$, treated with citral $(n=12)$, or mouthwash containing chlorhexidine digluconate at $1.2 \mathrm{mg} \mathrm{ml}^{-1}(\mathrm{CHX}$, positive control, $n=12$ ). The results were showed as mean $\pm S D$. One-way ANOVA and Tukey's Multiple Comparison post hoc test were used to compare data against the control data. *** $p<0.001$; ns: not significant.

\section{Discussion}

This study was delineated to include both initial dental colonizers and cariogenic species (S. gordonii, S. mitis, S. sanguinis, S. sobrinus, Actinomyces naeslundii, L. acidophilus and S. mutans), taking into account the complexity of cariogenic biofilm formation dynamics. The chemical composition, antimicrobial potential and cytotoxicity of $C$. citratus essential oil were investigated.

The GC/MS analysis detected more than $80 \%$ of citral in the oil composition. Citral was then used in some tests to investigate whether it was the main agent responsible for the antimicrobial activity of the essential oil.

The agar diffusion test was initially used to evaluate the antimicrobial activity of the essential oil. This is an easily performed test frequently used to screen the antimicrobial activity of natural products. ${ }^{26}$ Because an agar diffusion test is a semi-quantitative analysis, the diffusion capability of the testing compound may have been influenced by the chemical composition of the oils. ${ }^{27}$ For this reason, other tests with higher sensitivity were performed for the present study. These tests not only evaluated the antimicrobial activity of the essential oil using bacteria in suspension (MIC and MBC evaluation), but also how well it could prevent biofilm formation or kill the cells in a preformed structured biofilm. The analyses also included an assessment of the MIC and MBC of clinical isolates from carious dentine.

MIC (1.32 to $2.61 \mathrm{mg} \mathrm{ml}^{-1}$ ) and MBC (2.61 to $10.54 \mathrm{mg} \mathrm{ml}^{-1}$ ) values for the essential oil were similar to those obtained in a previous study, which showed the MIC of different extracts of $C$. citratus values ranging from $2.5 \mathrm{mg} \mathrm{ml}^{-1}$ to $10 \mathrm{mg} \mathrm{ml}^{-1}$ for streptococci species. ${ }^{15}$ C. citratus essential oil presented antimicrobial activity against several cariogenic species, including Streptococcus mutans and Lactobacillus acidophilus, which are frequently isolated from established carious cavities. ${ }^{5}$ These microorganisms were selected to perform further experiments in the present study.

The MIC and MBC values of citral on Streptococcus mutans and Lactobacillus acidophilus were very similar to those of the essential oil (Table 3), thus suggesting that citral was the main agent responsible for the antimicrobial activity of the oil.

In addition to evaluating antimicrobial activity in suspension, the authors found that $C$. citratus essential oil could promote promising antimicrobial activity against cariogenic bacteria in biofilms. The effects of the essential oil on bacterial adhesion to human dental enamel was initially tested. The results suggested that $C$. citratus essential oil significantly inhibited microorganisms from adhering to enamel surfaces. Inhibiting initial adhesion to enamel surfaces will inhibit all subsequent phases of biofilm formation in a cascade process.

The effect of the essential oil on preformed biofilm could be seen even after a short exposure time (60 seconds). However, the most significant results were obtained with a medium exposure time (60 minutes). In perspective, it would thus be interesting to develop formulations containing the present essential oil incorporated in a sustained release system that increases the drug exposure time and maintains the effective concentration in the oral cavity. Alternative formulations have been proposed to enhance the antimicrobial action of natural products, including chewing gum, ${ }^{28}$ sustained drug release systems ${ }^{29,30}$ and denture relining with resilient materials. ${ }^{31}$ This 
promising antimicrobial and antibiofilm potential may be applied as a basis for developing new preventive and therapeutic agents for dental caries.

To the best of our knowledge, this was the first time that the effect of $C$. citratus essential oil against polymicrobial biofilm was investigated. According to Cheng et al., ${ }^{21}$ polymicrobial biofilms obtained from human saliva are a useful model to evaluate antimicrobial activity.

Previous studies indicate that drug concentrations higher than the MIC are required to achieve an antibiofilm effect. ${ }^{32,33}$ In this study, preformed biofilms were eliminated at 2, 4 and 10 times MIC concentrations. The finding that $C$. citratus essential oil was able to eliminate preformed biofilm, even at concentrations close to MIC, points to this oil as a promising compound to incorporate into pharmaceutical formulations for oral use. The additive effect of adhesion inhibition and biofilm disruption is an important feature of $C$. citratus essential oil, because it could be used in two different clinical approaches: as an initial attack to revert the high caries risk of a patient while good oral hygiene habits are being acquired, and during the patient's preventive oral maintenance.

For the purpose of investigating whether citral could act on biofilm, in a way similar to the essential oil, a biofilm that requires a higher concentration of the oil to treat preformed streptococci biofilm in $48 \mathrm{~h}$ was selected. The results showed that citral was significantly effective in disrupting this mature biofilm, thus reinforcing the finding that the antibacterial activity of $C$. citratus essential oil can be attributed to high concentrations of citral (more than $80 \%$ ).
Plants produce natural products and secondary botanical compounds that can repel or kill other species, and thus be toxic to cells. ${ }^{34}$ Nonetheless, C. citratus essential oil was not cytotoxic, according to the classification by Sletten and Dahl, ${ }^{35}$ which considers a drug as severely, moderately or slightly cytotoxic, when the viability relative to the controls is less than $30 \%$, between $30 \%$ and $60 \%$, or greater than $60 \%$, respectively. It is worth citing that the cytotoxicity of chlorhexidine has been demonstrated, although it is still considered the gold standard substance for application in mouth rinses. Balloni et al. ${ }^{36}$ showed that chlorhexidine significantly reduced fibroblast and keratinocyte cell numbers in a short period of time.

Taken together, current data show that $C$. citratus essential oil has promising antimicrobial activity against primary dental colonizers and cariogenic species, and low cytotoxicity. The results suggest that citral may be responsible for the antimicrobial activity. These data point to the potential of this essential oil for the prevention of dental caries.

\section{Acknowledgements}

The authors wish to thank IPEN-CNEN/SP and CEBAPE - Centro de Biociências Aplicado a Pacientes Especiais, for their technical support.

\section{Funding}

This work was supported by FUNDUNESP. CAPES granted Master's fellowships to Oliveira MAC and Borges AC. AVL Gontijo is supported by FAPESP (\#2014/0966-4).

\section{References}

1. Dye BA, Thornton-Evans G. Trends in oral health by poverty status as measured by Healthy People 2010 objectives.

Public Health Rep. 2010;125(6):817-30.

https://doi.org/10.1177/003335491012500609

2. Kassebaum NJ, Bernabé E, Dahiya M, Bhandari B, Murray CJ, Marcenes W. Global burden of untreated caries: a systematic review and metaregression. J Dent Res. 2015;94(5):650-8 https://doi.org/10.1177/0022034515573272
3. Davey ME, O'toole GA. Microbial biofilms: from ecology to molecular genetics. Microbiol Mol Biol Rev. 2000;64(4):847-67. https://doi.org/10.1128/MMBR.64.4.847-867.2000

4. Soet JJ, Nyvad B, Kilian M. Strain-related acid production by oral streptococci. Caries Res. 2000;34(6):486-90. https://doi.org/10.1159/000016628

5. Takahashi N, Nyvad B. Caries ecology revisited: microbial dynamics and the caries process. Caries Res. 2008;42(6):409-18. https://doi.org/10.1159/000159604 
6. Baehni PC, Takeuchi Y. Anti-plaque agents in the prevention of biofilm-associated oral diseases. Oral Dis. 2003;9(s1 Suppl 1) 23-9. https://doi.org/10.1034/i.1601-0825.9.s1.5.x

7. Sreenivasan P, Gaffar A. Antiplaque biocides and bacterial resistance: a review. J Clin Periodontol. 2002;29(11):965-74. https://doi.org/10.1034/j.1600-051X.2002.291101.x

8. Parwani SR, Parwani RN, Chitnis PJ, Dadlani HP, Prasad SV. Comparative evaluation of anti-plaque efficacy of herbal and $0.2 \%$ chlorhexidine gluconate mouthwash in a 4 -day plaque re-growth study. J Indian Soc Periodontol. 2013;17(1):72-7. https://doi.org/10.4103/0972-124X.107478

9. Ledder RG, Latimer J, Humphreys GJ, Sreenivasan PK, McBain AJ. Bacteriological effects of dentifrices with and without active ingredients of natural origin. Appl Environ Microbiol. 2014;80(20):6490-8. https://doi.org/10.1128/AEM.02315-14

10. Quintas V, Prada-López I, Prados-Frutos JC, Tomás I. In situ antimicrobial activity on oral biofilm: essential oils vs. 0.2 \% chlorhexidine. Clin Oral Investig. 2015;19(1):97-107. https://doi.org/10.1007/s00784-014-1224-3

11. Gordon JM, Lamster IB, Seiger MC. Efficacy of Listerine antiseptic in inhibiting the development of plaque and gingivitis. J Clin Periodontol. 1985;12(8):697-704. https://doi.org/10.1111/j.1600-051X.1985.tb00941.x

12. Verkaik MJ, Busscher HJ, Jager D, Slomp AM, Abbas F, Van der Mei HC. Efficacy of natural antimicrobials in toothpaste formulations against oral biofilms in vitro. J Dent. 2011;39(3):218-24. https://doi.org/10.1016/i.jdent.2010.12.007

13. Wang Y, Lee SM, Dykes GA. Potential mechanisms for the effects of tea extracts on the attachment, biofilm formation and cell size of Streptococcus mutans. Biofouling. 2013;29(3):307-18. https://doi.org/10.1080/08927014.2013.774377

14. Senatore F, Arnold NA, Piozzi F. Chemical composition of the essential oil of Salvia multicaulis Vahl. var. simplicifolia Boiss. growing wild in Lebanon. J Chromatogr A. 2004;1052(1-2):237-40. https://doi.org/10.1016/i.chroma.2004.08.095

15. Ambade SV, Bhadbhade BJ. In vitro comparison of antimicrobial activity of different extracts of Cymbopogon citratus on dental plaque isolates. Int J Curr Microbiol Appl Sci. 2015;4(7):672-81.

16. Almeida RB, Akisue G, Cardoso LM, Junqueira JC, Jorge AC. Antimicrobial activity of the essential oil of Cymbopogon citratus (DC) Stapf. on Staphylococcus spp., Streptococcus mutans and Candida spp. Rev Bras Plantas Med. 2013;15(4):474-82. https://doi.org/10.1590/S1516-05722013000400002

17. Rego CB, Silva AM, Gonçalves LM, Paschoal MA. In vitro antimicrobial activity of essential oil of Cymbopogon citratus (lemon grass) on Streptococcus mutans biofilm. Afr J Microbiol Res. 2016;10(31):1224-8. https://doi.org/10.5897/AJMR2016.8216

18. Tofiño-Rivera A, Ortega-Cuadros M, Galvis-Pareja D, Jiménez-Rios H, Merini LJ, Martínez-Pabón MC. Effect of Lippia alba and Cymbopogon citratus essential oils on biofilms of Streptococcus mutans and cytotoxicity in $\mathrm{CHO}$ cells. J Ethnopharmacol. 2016;194:749-54. https://doi.org/10.1016/i.jep.2016.10.044

19. Adams RP. Identification of essential oil components by gas chromatography/mass spectrometry. 4th ed. Carol Stream, IL: Allured; 2007.

20. Johnston C. The Wiley / NBS Registry of Mass Spectral Data, Volumes 1-7 (McLafferty, Fred W.; Stauffer, Douglas B.). J Chem Educ. 1989;66(10):A256. https://doi.org/10.1021/ed066pA256.3

21. Cheng L, Exterkate RA, Zhou X, Li J, ten Cate JM. Effect of Galla chinensis on growth and metabolism of microcosm biofilms. Caries Res. 2011;45(2):87-92. https://doi.org/10.1159/000324084

22. Bruschi ML, Lara EH, Martins $\mathrm{CH}$, Vinholis AH, Casemiro LA, Panzeri $\mathrm{H}$ et al. Preparation and antimicrobial activity of gelatin microparticles containing propolis against oral pathogens. Drug Dev Ind Pharm. 2006;32(2):229-38. https://doi.org/10.1080/03639040500466312

23. Clinical and Laboratory Standards Institute. Methods for dilution antimicrobial susceptibility tests $f$ or bacteria that grow aerobically: approved standard. 9th ed. Wayne, PA: Clinical and Laboratory Standards Institute; 2012.

24. Exterkate RA, Crielaard W, Ten Cate JM. Different response to amine fluoride by Streptococcus mutans and polymicrobial biofilms in a novel high-throughput active attachment model. Caries Res. 2010;44(4):372-9. https://doi.org/10.1159/000316541

25. Mosmann T. Rapid colorimetric assay for cellular growth and survival: application to proliferation and cytotoxicity assays. J Immunol Methods. 1983;65(1-2):55-63. https://doi.org/10.1016/0022-1759(83)90303-4

26. Jeon JG, Rosalen PL, Falsetta ML, Koo H. Natural products in caries research: current (limited) knowledge, challenges and future perspective. Caries Res. 2011;45(3):243-63. https://doi.org/10.1159/000327250

27. Cos P, Vlietinck AJ, Berghe DV, Maes L. Anti-infective potential of natural products: how to develop a stronger in vitro 'proof-of-concept'. J Ethnopharmacol. 2006;106(3):290-302. https://doi.org/10.1016/i.jep.2006.04.003

28. Ercan N, Erdemir EO, Ozkan SY, Hendek MK. The comparative effect of propolis in two different vehicles; mouthwash and chewing-gum on plaque accumulation and gingival inflammation. Eur J Dent. 2015;9(2):272-6. https://doi.org/10.4103/1305-7456.156851

29. Franca JR, De Luca MP, Ribeiro TG, Castilho RO, Moreira AN, Santos VR et al. Propolis_based chitosan varnish: drug delivery, controlled release and antimicrobial activity agains $†$ oral pathogen bacteria. BMC Complement Altern Med. 2014;14(1):478. https://doi.org/10.1186/1472-6882-14-478

30. Al Dehailan L, Martinez-Mier EA, Lippert F. The effect of fluoride varnishes on caries lesions: an in vitro investigation. Clin Oral Investig. 2016;20(7):1655-62. https://doi.org/10.1007/s00784-015-1648-4 
- Cymbopogon citratus essential oil: effect on polymicrobial caries-related biofilm with low cytotoxicity

31. Bueno MG, Urban VM, Barbério GS, da Silva WJ, Porto VC, Pinto $L$ et al. Effect of antimicrobial agents incorporated into resilient denture relines on the Candida albicans biofilm. Oral Dis. 2015;21(1):57-65. https://doi.org/10.1111/odi.12207

32. Chandra J, Mukheriee PK, Leidich SD, Faddoul FF, Hoyer LL, Douglas $L J$ et al. Antifungal resistance of candidal biofilms formed on denture acrylic in vitro. J Dent Res. 2001;80(3):903-8. https://doi.org/10.1177/00220345010800031101

33. Douglas LJ. Candida biofilms and their role in infection. Trends Microbiol. 2003;11(1):30-6. https://doi.org/10.1016/S0966-842X(02)00002-1
34. Mazid M, Khan TA, Mohammad F. Role of secondary metabolites in defense mechanisms of plants.

Biology and medicine. 2011;3(2 spec issue):232-49.

35. Sletten GB, Dahl JE. Cytotoxic effects of extracts of compomers. Acta Odontol Scand. 1999;57(6):316-22. https://doi.org/10.1080/000163599428544

36. Balloni S, Locci P, Lumare A, Marinucci L. Cytotoxicity of three commercial mouthrinses on extracellular matrix metabolism and human gingival cell behaviour. Toxicol In Vitro. 2016;34:88-96. https://doi.org/10.1016/i.tiv.2016.03.015 